\title{
The Effect of Mesenchymal Punca Cell in Scaffold Primo to Fusion of Vertebral Column After Laminoplasty
}

\author{
Roni Eka Sahputra ${ }^{1}$, Yanwirasti ${ }^{2}$, Rahyussalim Ahmad Jabir ${ }^{3}$, and Yudan Whulanza ${ }^{4}$ \\ \{roni78esahputra@gmail.com ${ }^{1}$ \} \\ Orthopaedic Division of Surgical Departement, Medical Faculty of Andalas University/Dr. M.Djamil \\ Hospital Padang - West Sumatera ${ }^{1}$ \\ Anatomy Division, Medical Faculty of Andalas University ${ }^{2}$ \\ Orthopaedic Division of Surgical Departement, Medical Faculty of Indonesia University/RSUP Cipto \\ MAngunkusumo, Jakarta, Indonesia ${ }^{3}$ \\ Mechanical Faculty of Indonesia University ${ }^{4}$
}

\begin{abstract}
Spinal abnormalities, especially spinal stenosis, are currently a common problem with a range of $65 \%$ of the entire population experiencing low back pain resulting in a decrease in quality of life. Along with its development, various Laminoplasty methods have developed until the use of biomaterials as a substitute for autograft combined with mesenchymal stem cells which are thought to provide better results in tissue regeneration. This research is purely experimental with post-test content group only design, where using 16 rabbits as a sample will be divided into 4 groups and 3-dimensional scaffold with pure polymeric materials carried out from May 2017 to July 2017. The study found a tendency to increase cell numbers osteoblasts in the treatment group when compared with controls and statistically this increase was significant $(\mathrm{p}<0.05)$. From this study, we found that administration of mesenchymal stem cells in primo scaffold can increase the number of osteoblasts to accelerate post Laminoplasty fusion.
\end{abstract}

Keywords: Laminoplasty, Mesenchymal Punca Cells (MPC), Osteoblast.

\section{Introduction}

Generally, Life expectancy has increased from the age of 67 years in 2009 to 71 years in 2013. Indonesia is predicted to experience an increase in the elderly population in 2025 by $301 \%$ of the elderly population in 1985 [1]. With the increase in the elderly population, it can be ascertained that degenerative diseases due to aging will increase. One of the affected organ systems is musculoskeletal. The vertebral column is one that is affected by degenerative diseases of the spine.

Spinal abnormalities at this time are a problem that often occurs with increased incidence every year - about $65 \%$ of the entire population experiences low back pain. This situation will cause the quality of life to decline and much expenditure. The part that is often affected is the neck and waist. The basic pathology of pain can be abnormalities inside or outside the spine. Every year $16.6 \%$ of the adult population complains of bad neck feeling, even $0.6 \%$ continues to be severe neck pain. The incidence of neck pain increases with age. More often about men than women with a ratio of 1.67: 1 [2]. 
The spine is a vital organ that supports the human body which is an integration of bones, ligaments, muscles, nerves, and blood vessels. These bones are arranged in such a way with the gaps that are where the spinal cord passes. Various things can cause this gap to narrow (stenosis), causing clamping and even nerve injury causing morbidity and disability from tingling, numbness, muscle weakness, paralysis to disruption of the function of the micturition and defecation [3].

This spinal stenosis is the most case in the degenerative process in the spine. Stenosis can occur in the central region, lateral recess, or in the foramen where the root extract from the spinal cord is released [3]. Many attempts to free nerve pins have been carried out by decompression, both with the anterior and posterior approaches. In stenosis with multiple cervical regions, the technique of decompression with laminectomy alone is not enough and often leads to kyphosis due to reduced muscle strength to hold cervical bones and reduced neck movement due to fusion. However, with the technique of laminoplasty, decompression can be achieved while maintaining neck movement [4].

Laminoplasty is a surgical technique for decompressing the spinal cord and neuroforamen by reconstructing the lamina arch through the posterior side of the vertebra. Various types of laminoplasty techniques have been carried out. In the Hirabayasi technique, reconstruction is carried out to make the hinge where the lamina is lifted but not released. The technique of lamina reconstruction or laminoplasty by lifting the lamina on one side aims to release pressure on the spinal cord (decompression) [5]. The Kurokawa laminoplasty technique is a more symmetrical reconstruction technique where the gap is made in the middle by splitting the spinous process and making two hinges in the left and right hemilamina (two-door) [6].

According to development, several techniques have been proposed to fill the gaps that form and protect the spinal cord, including autograft of the spinous process which is fixed by wire, autograft of the iliac crest or rib. Autograft is the gold standard regarding stimulating the achievement of osteogenesis, osteoinductive, and also as osteoconductive. However, in the use of autograft also brings morbidity which is also very disturbing to patients. Graft adequacy to be taken is also limited to morbidity at the place of graft taking and the risk of infection, so this is also what causes the decision to switch to other options. Furthermore, the allograft has been used, but the osteoinductive effect is very minimal, availability is limited, and in recent developments, it begins to think in other forms, namely biomaterials such as hydroxyapatite or ceramics. Some are fixated with threads, wires, and also with the use of mini implants in lamina that are carried out by laminoplasty [7].

Bone healing is a repetition of the process that occurs in the embryonic period of endochondral bone formation. Based on histology appearance, the process can be divided into two, primary and secondary healing. Primary healing is rare and is possible only if there is no distance between fragments (absolute contact) or with minimal distance. Whereas, the secondary bone healing occurs mostly in bone disruption consisting of both intramembranous and endochondral ossification and callus formation and involves activation of mesenchymal punca cells (MPC) that are both in the periosteum and endosteum.

All tissue can be a source of MPC. In bone healing these cells can originate from the periosteum, soft tissue around the bone, bone marrow, and endosteum. Stem cells can renew themselves for a long time without changing their structure significantly and can be stimulated to differentiate into various types of cells desired, forming certain tissues for therapeutic purposes with structures and mechanical properties that are by physiological conditions, and can integrate perfectly with the surrounding tissue. Because of these characteristics, MPC proved effective as a therapy for tissue injury. 
Currently, the laminoplasty technique is done in Indonesia, especially in Cipto Mangunkusumo Hospital (RSCM) using allografts in the form of synthetic bone braces made from hydroxyapatite (HA) which are imported from abroad. The use of allograft import certainly adds a significant operating expense to the laminoplasty procedure which costs a lot. In M. Djamil Hospital there have also been many cases of laminoplasty using autografts from the spinous process.

Along with the increasing prevalence of spinal canal stenosis which has high morbidity and affects the quality and productivity of patients' lives, the number of cases of laminoplasty is increased too. By producing its spacers for laminoplasty, it is expected that the shape can be more tailored to the size of patients in Indonesia, accelerating the healing process by adding osteoinductive stem cells such as MPC. Mesenchymal punca cells originating from the bone marrow have the potential to differentiate into different hereditary cells, including osteoblasts, chondrocytes, adipocytes, tenocytes, and cell stroma marrow cells.

Based on the above and preliminary research on scaffold material, this study was conducted to prove the effect of the scaffold with MPC on spinal regeneration. This research is important to see how scaffold planted with stem cells can be a strong buffer and good fusion at levels that are done by laminoplasty so that it will reduce morbidity and improve the quality of life for patients. The aim of the study to analyze effect application MPC to scaffold to spinal fusion after laminoplasty.

\section{Materials and methods}

The spinal tissue sample was taken from 16 rabbits that were carried out with laminoplasty from May 2017 to July 2017. Laminoplasty was performed Immunology Laboratory of Andalas University. Schaffold used is a scaffold designed by Engineering Laboratory of Indonesia University. The Mesenchymal stem cells used came from the Stem Cell Technology Development Unit of Cipto Mangunkusomo Hospital. Whereas for the histopathological examination of osteoblasts performed at the Anatomical Pathology Laboratory of the Medical Faculty of Andalas University.

\section{Results}

Based on the results of the study, it was found that there was a difference in the average number of osteoblasts based on the treatment group. There are increasing number of osteoblast start from the control group to the $3^{\text {rd }}$ group. Statistically, the difference was significant ( $\mathrm{p}$ $<0.05)$.

Table 1. Differences in the Average Number of Osteoblasts based on the Treatment Group

\begin{tabular}{|c|c|c|c|c|c|}
\hline \multirow{2}{*}{ Group } & \multicolumn{2}{|c|}{ Osteoblast } & \multicolumn{2}{|c|}{ 95\% Confidence Interval for Mean } & \multirow[b]{2}{*}{$-p$} \\
\hline & Mean & Std. Deviation & Lower Bound & Upper Bound & \\
\hline Control & 3,75 & 6,36 & $-6,36$ & 13,86 & \multirow{4}{*}{0,001} \\
\hline $1^{\text {st }}$ Group & 4,00 & 1,26 & 1,99 & 6,01 & \\
\hline $2^{\text {nd }}$ Group & 7,05 & 1,92 & 3,98 & 10,11 & \\
\hline $3^{\text {rd }}$ Group & 18,85 & 4,76 & 11,28 & 26,42 & \\
\hline
\end{tabular}


Table 2. Result Post Hoc test (Bonferroni) between treatment group to the number of osteoblasts

\begin{tabular}{lllll}
\hline Group & Control & $1^{\text {st }}$ Group & $2^{\text {nd }}$ Group & $3^{\text {rd }}$ Group \\
\hline Control & & 1,00 & 1,00 & 0,001 \\
$1^{\text {st }}$ Group & 1,00 & & 1,00 & 0,002 \\
$2^{\text {nd }}$ Group & 1,00 & 1,00 & & 0,01 \\
$3^{\text {rd }}$ Group & 0,001 & 0,002 & 0,01 & \\
\hline
\end{tabular}

The table demonstrates that there are significant differences in the average number of new osteoblasts occurred between the control group and $3^{\text {rd }}$ Group $(\mathrm{p}<0.05)$. This also happened between $1^{\text {st }}$ and $2^{\text {nd }}$ Group with $3^{\text {rd }}$ Group.

\section{Discussion}

Osteoblasts are known as the cells responsible for a bone formation that produce new bone, and osteoclast responsible for bone resorption which breaks down the bones. Osteoblasts originate from mesenchymal stem cells (SPM) located in the bone marrow, and osteoclasts are produced from hematopoietic stem cells (HSCs). TGF- $\beta$ controls the differentiation of osteoblasts and osteoclasts, and keep balance formation and resorption of bone

Osteoblasts are mononucleosis cells that are responsible for bone formation. They originate from osteoblastic precursors located in the deeper layers of the periosteum and bone marrow and produce an osteoid matrix, which consists mainly of type I collagen. TGF- $\beta$ has various roles that are widely known in bone formation. For example, TGF- $\beta$ increases osteoblast proliferation, inhibits osteoblast apoptosis, and also recruits osteoblastic precursors or matrixproducing osteoblasts to locations via chemotactic attraction. Also, TGF- $\beta$ increases the production of extracellular bone matrix proteins by osteoblasts in the early stages of osteoblast differentiation.

Similar result from study by Granero (2009), that in each group both injected stem cells with the type CMV-Cre-R26R-LacZ-MSC and the control group, osteoblasts were found to be the same, but differentiated by current coloring, specifically for these stem cell types, it was found that there were osteoblasts that matched the type of stem cells included, this indicates that these stem cells differentiate into osteoblasts seen from the growth of callus with a diameter greater than the diameter of the control group.

Bone is a very vascular tissue with intrinsic properties to repair, regenerate and remodel itself. This is an excellent ability to cure traumatic wounds (e.g. fractures) without scar formation. However, there are still some clinical scenarios where their self-repairing and regenerative abilities fail. Some classic examples include large bone defects caused by traumatic wounds, infections, tumor resection and skeletal abnormalities due to congenital diseases [8]. 
Stem cells combined with biomaterials and implanted into lesions and the use of tissue engineering techniques are considered as promising strategies for treating bone abnormalities. Some small animal studies have shown that treating bone defects with a combination of biomaterials and SPM can improve bone regeneration. Human bone marrow SPM and calcium macropore phosphate cement are combined and transplanted into critical cranial defects in mice. Construction produces more new bone and blood vessels than cells calcium phosphate cement control $[9,10]$.

\section{References}

[1] World Health Organization, WHO.(2015)Global Health Observatory data repository: Life Expectancy - Data by Country. Geneva. Diunduh dari http://apps.who.int/gho/data/node.main.688?lang=en tanggal 14 februari 2017

[2] Eberaold MJ, Raynor RB: Cervical laminotomy, laminectomy, laminoplasty, and foraminotomy. E. Benzel, editors. $2^{\text {nd }}$ ed. Elsevier, Philadelphia, 387-394,2005

[3] Martini, FH. 2006. “Fundamental of Anatomy \& Physiology". International Edition. 7.

[4] Fateh, M et all. 2013 "The Effect of Expansive Open Door Laminoplasty on Spinal Canal Diameter: an Experimental Study on Rabbits". Acta Orthop Traumatol Turc. 47 (2), 1-4

[5] Hirabayashi K, Toyama Y, Chiba K, et al., Expansive laminoplasty for myelopathy in ossification of the longitudinal ligament. Clin Orthop, 359: 35-48. 1999

[6] Kurokawa R, Kim P. Cervical laminoplasty: The history and the future. Neurol Med Chir. 2015;55:529-39.

[7] Ahlmann E, Patzakis M, Roidis N, Shepherd L, Holtom P (2002) Comparison of anterior and posterior iliac crest bone grafts regarding harvest-site morbidity and functional outcomes. J Bone Jt Surg Am 84(5):716-720

[8] Raynor RB, Pugh J, Shapiro I. Cervical facetectomy and its effect in spine strength. J Neurosurg 63: 278-292. 1985

[9] Horwitz EM, Prockop DJ, Fitzpatrick LA, Koo WW, Gordon PL, Neel M, et al. Transplantability and therapeutic effects of bone marrow-derived mesenchymal cells in children with osteogenesis imperfecta. Nat Med (1999) 5(3):309-13. doi:10.1038/6529

[10] Najib El Haddad. Mesenchymal stem cells: Imunology and Therapeutic Benefits. Stem cells in clinic and research. Book edited by Ali Gholamrezanezhad. ISBN 978-953-307-797-0. Published August 2011 